\title{
PONTES DE CONVERGÊNCIA ENTRE A NOÇÃO DE SABER AMBIENTAL E O PERFIL ESPERADO DE UM ENGENHEIRO
}

\author{
CONVERGENCE BRIDGES BETWEEN THE NOTION OF ENVIRONMENTAL \\ KNOWLEDGE AND THE EXPECTED PROFILE OF AN ENGINEER
}

\author{
P. B. de CARVALHO ${ }^{1, *}$; C. C. B. de FREITAS ${ }^{1} ;$ e J. G. PEDROSA ${ }^{1}$
}

1 Centro Federal de Educação Tecnológica de Minas Gerais, Programa de Pós-Graduação em Educação Tecnológica, Brasil.

\section{ARTICLE INFO}

Article history:

Received 2018-07-03

Accepted 2018-12-20

Available online 2018-12-21

*Autor correspondente:

E-mail: polianabelmon@gmail.com
Palavras-chave: Perfil do engenheiro. Saber ambiental. Educação em engenharia.

Keywords: Profile of the engineer. Environmental Knowledge. Engineering education.

RESUMO. Este artigo reflete as relações entre o saber ambiental e o perfil de futuros engenheiros a partir da análise das Diretrizes Curriculares Nacionais do Curso de Graduação em Engenharia. Ao situar alguns conceitos e discussões acerca da crise ambiental sob a ótica de diferentes autores, o trabalho, resultado de uma revisão bibliográfica, tem por objetivo investigar se há na formação profissional do futuro engenheiro a presença de formação ética, social e ambiental. A partir dessa ideia central, o artigo objetiva compreender como o saber ambiental discutido por Enrique Leff contribui para a formação do engenheiro. Para isso, apresenta-se as características do perfil esperado do futuro engenheiro a partir da Resolução 11/2002 e traça-se pontos em comum e divergentes da mesma em relação à noção de saber ambiental. Tal análise permitiu perceber que o perfil dos egressos segundo as diretrizes é predominantemente, técnica e especialista, contrariando, a proposta de formação de um profissional generalista e crítico.

\begin{abstract}
This article reflects the relationships between environmental knowledge and the profile of future engineers from the analysis of the National Curricular Guidelines for engineering degree course. By rescuing some concepts and debates about the environmental crisis from different authors' perspectives, this paper, the result of a literature review, aims to investigate if there is in the training of future engineers, an ethical, social and environmental qualification. From this central idea, the article aims to understand how the environmental knowledge discussed by Henrique Leff contributes to the training of engineers. For this, having the Resolution 11/2002 as a guideline, the characteristics of the expected profile of the future engineer are presented, and a common and divergent point are drawn in relation to the notion of environmental knowledge. This analysis made it possible to perceive that the training of the engineer is, predominantly, technical and specialist, contrary to the proposal of formation of a generalist and critical professional.
\end{abstract}




\section{Introdução}

Desde tempos remotos, bem antes mesmo do advento da civilização industrial e da massificação do consumo, o homem investe em conhecer e modificar a natureza para dela usufruir como meio e como recurso para suprir suas necessidades, desejos e obsessões. Essa exploração do ambiente natural gerou uma complexa transformação nos ecossistemas e nas dinâmicas naturais (RABELO, 2007, apud LOPES, 2014).

Observa-se no atual cenário mundial um enfraquecimento dos recursos naturais devido à poluição do ar, da água e do solo por dejetos não controlados na produção industrial; o empobrecimento da fauna e da flora devido a extinção de espécies; e a ruptura de certos equilíbrios ecológicos globais, o que evidentemente, não são mais novidades. Este atual modelo de desenvolvimento industrial, que condiciona até mesmo a ciência e a técnica, pode ser considerado o responsável pelo aumento alarmante da destruição da natureza e, consequentemente, pela crise ecológica (BIHR, 1998).

Pode-se considerar a crise ecológica também como uma crise da democracia. Para Leff (2015), assim como para Bihr (1998), a crise é mais do que ecológica, é uma crise ambiental que atinge também os âmbitos social, político e econômico. A degradação da natureza, o esgotamento ecológico, a disparidade entre ricos e pobres e a fragmentação do conhecimento são os sinais mais evidentes da crise do mundo globalizado. A crise é o efeito do pensamento ocidental com o qual se constrói e se destrói o mundo, com o qual produziu a separação homem-natureza, que abriu espaço para a racionalidade instrumental e tecnológica e que criou um mundo fragmentado e coisificado. A crise ambiental, para Leff (2015), fomenta uma reflexão sobre os fundamentos do saber e o sentido da vida que regem a sociedade capitalista.

Este cenário nos mostra um crescimento econômico que desvaloriza o ser humano, a cultura e a natureza e desvela uma dívida séria: a dívida da razão. Essa dívida surgiu pela imposição de uma razão econômico-tecnológica que domina o homem. Essa razão tirou a liberdade, a democracia e o pensamento crítico e por isso ficamos à deriva, ou seja, sem rumos claramente definidos.

A crise ambiental e, consequentemente, a dívida da razão, levam ao questionamento do funcionamento das sociedades contemporâneas, a maneira como estas lidam com a natureza, os atuais meios de produção e formas de consumo, os produtos resultantes da atividade econômica, o modo de vida dos indivíduos e, não menos importante, a superestimação da técnica associada e a fragmentação da ciência. (BIHR, 1998).

Assim, diante das novas normas de consumo, a natureza se vê reprimida pelo capital, onde os padrões de consumo que passam a vigorar não respeitam os ciclos naturais, a dinâmica dos ecossistemas, a capacidade de suporte e a regeneração da 
natureza. Com isso ocorre um agravamento da degradação do ambiente e consequentemente o surgimento de desastres ambientais, onde os problemas decorrentes desses fatos se tornaram mais visíveis, culminando no reconhecimento por parte de cientistas ambientais, de movimentos ambientalistas e, posteriormente, da Organização das Nações Unidas (ONU), de uma crise ambiental a partir dos anos 1960 (LEFF, 2015).

Os novos cenários mundiais que são apresentados pelos avanços tecnológicos, científicos, pelas conquistas da humanidade e pelo uso intensivo dos recursos naturais, possibilita a uma reflexão de como o conhecimento vem sendo gerado (MORAES, 1997). Diante das questões ambientais, da mudança na forma de produção e das novas exigências sociais, emerge uma necessidade de renovar os currículos dos sistemas formais de educação, promover e fomentar a formação crítica.

No âmbito do ensino superior, a área de Engenharia tem buscado suprir as necessidades do mercado e da sociedade no que diz respeito à formação do engenheiro, dentro de um contexto ético, social e ambiental (LOPES, 2014). Segundo Laudares (1992), o profissional engenheiro desenvolve suas atividades dentro da área de tecnologia, gerando bens para a sociedade a partir de processos industriais e da produção científica disponível. A transformação no teor das atividades dos engenheiros e nas suas atribuições tem como implicação a necessidade de qualificações especificas. O perfil deste profissional é definido pela Resolução 11/2002 do Conselho Nacional de Educação:

O curso de engenharia tem como perfil do formando egresso/profissional o engenheiro, com formação generalista, humanista, crítica e reflexiva, capacitado a absorver e desenvolver novas tecnologias, estimulando a sua atuação crítica e criativa na identificação e resolução de problemas, considerando seus aspectos políticos, econômicos, sociais, ambientais e culturais, com visão ética e humanística, em atendimento às demandas da sociedade. (BRASIL, Resolução 11/2002, p. 1, que regulamentou as Diretrizes Curriculares Nacionais para os cursos de engenharia).

Neste contexto, o presente artigo, de cunho teórico, resulta de pesquisa bibliográfica que teve por finalidade investigar se o perfil esperado de um engenheiro está associado a uma formação ética, social e ambiental. Em outras palavras, o artigo objetiva compreender como o saber ambiental de Leff (2015) está prescrito para a formação de um engenheiro. Para isso, pretende-se identificar pontes de convergência que são, na perspectiva deste artigo, ideias que permitem relacionar a noção de saber ambiental e as Diretrizes Curriculares Nacionais dos Cursos de Graduação em Engenharia. Essa relação pode ser tanto de aproximação, ou seja, na presença de semelhanças, bem como de distanciamento, ou seja, na presença de diferenças entre o saber ambiental e as diretrizes.

$\mathrm{O}$ artigo está dividido em quatro sessões, sendo a primeira referente à apresentação do método desta pesquisa. A segunda sessão, por sua vez, é a fundamentação do tema, ou 
seja, aquela que dá embasamento ao enfoque da questão abordada e à discussão da mesma - o saber ambiental. Tal sessão aborda a noção de saber ambiental a partir da diferença entre as racionalidades instrumental e tecnológica e suas relações com a racionalidade ambiental. A terceira sessão contém a discussão acerca do perfil esperado de um engenheiro e sua relação com o saber ambiental. Esta sessão, portanto, aborda as pontes de convergência, ou em outros termos, as semelhanças e, também, as diferenças entre a noção de saber ambiental e o perfil esperado de um engenheiro conforme as diretrizes dos cursos de graduação em Engenharia. Nas considerações finais, por fim, pretende-se refletir sobre a importância de uma nova prática educativa que ajude na constituição de um sujeito capaz de agir sustentavelmente na sociedade em que está inserido.

\section{Método}

O presente artigo ${ }^{1}$ constitui-se de revisão da literatura acerca do saber ambiental e de assuntos relacionados à formação de engenheiros, temas estes abordados nas dissertações de mestrado dos autores. Este estudo foi realizado entre junho de 2016 e dezembro de 2017, no qual realizou-se uma consulta a livros e periódicos presentes na biblioteca do Centro Federal de Educação Tecnológica de Minas Gerais (CEFET-MG) campus II, e no banco de teses e dissertações da Coordenação de Aperfeiçoamento de Pessoal de Nível Superior (CAPES).

Nesse levantamento, muitos trabalhos com temas correlatos abordavam Enrique Leff como um dos teóricos que fundamentavam a pesquisa sobre o "saber ambiental", e é por esta razão que aqui, também, o autor se apresenta como o principal referencial teórico. Leff (2015) tem uma análise realista frente ao reconhecimento da espécie humana como incapaz de se perceber fazendo parte integrante da natureza. Leff (2015) trata a crise ambiental não apenas como uma questão ecológica, mas também como questão política e social. O autor adota uma postura crítica ao capitalismo e enfatiza que a racionalidade imposta por esse modo de produção e de vida visa à obtenção de lucro e gera a devastação da natureza e a desigualdade social em diversos lugares do mundo. Assim, buscando-se analisar o saber ambiental na formação do engenheiro, associou-se à noção de saber ambiental de Leff (2015) às Diretrizes Curriculares Nacionais dos Cursos de Graduação em Engenharia (2002) já que tais diretrizes definem os princípios, fundamentos, condições e procedimentos da formação de engenheiros.

\footnotetext{
${ }_{1}^{1}$ Artigo apresentado no VII Simpósio Internacional - SITRE - Trabalho, Relações de Trabalho, Educação e Identidade. Realizado no período de 28 a 30 de maio de 2018 em Belo Horizonte- MG.
} 


\section{O saber ambiental}

Para entendimento da noção de "saber ambiental" conforme a definição de Enrique Leff (2015) é importante salientar a complexidade envolvida por este conceito. Para isso fazse necessário a explanação do termo "racionalidade", e no que tange a isso, os filósofos sociais da Escola de Frankfurt são referências. Max Horkheimer distingue, em seu livro Eclipse da razão (2010), dois tipos de razão: a cognitiva e a instrumental. A cognitiva consiste na busca de novas verdades e novos conhecimentos, a instrumental, por sua vez, é aquela que consiste no agir do homem sobre a natureza a fim de transformá-la. Com a valorização da técnica e o advento do capitalismo, a razão instrumental se impôs sobre a cognitiva. Para Horkheimer, tal sobreposição racional permitiu a dominação da natureza para fins lucrativos e colocou a ciência e a técnica a serviço do capital.

Outro autor frankfurtiano que pode ser relacionado á discussão sobre racionalidade é Herbert Marcuse, que traz à tona o conceito de racionalidade tecnológica. Em seu texto Algumas implicações sociais da tecnologia moderna, Marcuse (1999), relaciona racionalidade e tecnologia. Para ele, a técnica pode tanto promover a liberdade como 0 autoritarismo, mas neste contexto, a racionalidade tecnológica vem estabelecendo padrões de vida para o indivíduo humano, ou seja, tirando a sua liberdade e incentivando o autoritarismo. Segundo Marcuse, por meio da racionalidade tecnológica o indivíduo se vê coagido a adaptar-se ao aparato da sociedade-máquina.

Apontando para uma ruptura com os paradigmas impostos pela racionalidade instrumental e tecnológica que tendem ao domínio tanto do homem quanto da natureza pelos imperativos do capital, o mexicano Enrique Leff apresenta a ideia de racionalidade ambiental. Tal racionalidade surge a partir de um novo conceito de ambiente que, por sua vez, ressignifica as concepções de progresso, desenvolvimento e crescimento sem limites, de modo a "[...] configurar uma nova racionalidade social que reflete no campo da produção e do conhecimento, da política e das práticas educativas." (LEFF, 2015, p.11). A racionalidade ambiental nega a lógica da capitalização da natureza e contém um conjunto de significações, normas, valores, interesses e ações socioculturais que primam pela sustentabilidade.

Em tempos nos quais prevalece a tecnologização da vida e a economização da natureza, surge também a necessidade de se construir uma racionalidade alicerçada em novos valores. Valores esses que orientem a construção da racionalidade ambiental estruturada por um novo saber questionador, transformador e recreativo, que desvele a enganosa transparência dos sinais do mercado globalizado e do iluminismo do conhecimento científico e moderno. Nesta nova racionalidade, fundem-se a razão e o 
desejo, a ética e o conhecimento, o pensamento racional e a sensualidade da vida. A racionalidade ambiental abre caminho para uma reerotização do mundo, transgredindo a ordem atual a qual se impõe a submissão das subjetividades. Portanto, para a construção da racionalidade ambiental é indispensável o rompimento com a racionalidade instrumental e tecnológica hegemônica (LEFF, 2015).

O saber ambiental é um saber que desperta para a necessidade de mudanças sociais já que promove mudanças epistemológicas. No que tange ao saber ambiental, Leff afirma: é "[...] atravessado por estratégias de poder em torno da reapropriação da natureza." (LEFF, 2015, p.10). Reapropriação esta, que envolve a sensação, a memória, a experimentação, a arte e a ciência. Esse saber não é simplesmente a realidade visível da poluição ou do desmatamento, por exemplo, mas sim um saber que interpõe o pensamento e o mundo, a sociedade e a natureza, a biologia e a tecnologia, a vida e a linguagem, o habitat e o habitar. Esse novo saber surge do espaço de exclusão gerado no desenvolvimento das ciências modernas centradas em seus objetos de conhecimento. Portanto, o saber ambiental vai contra a ideia positivista e, não obstante, valoriza a construção do conhecimento a partir de processos complexos. O saber ambiental é crítico e complexo e integra os processos de ordem natural, técnica e social, mas nunca os uniformiza. Ele valoriza a multiplicidade de experiências e práticas de cada cultura e, a partir de sua diversidade, estrutura esta nova racionalidade (LEFF, 2015).

Leff (2015) afirma que o saber ambiental não é exclusivo das disciplinas ambientais, já que sua abrangência vai além das causas estritamente ecológicas. O conceito de saber ambiental abrange ética, conhecimentos práticos e até mesmo saberes tradicionais. Segundo o autor, o saber ambiental vai em oposição ao método científico moderno centrado em seus micro objetos de pesquisa que, por diversas vezes, desconhecem processos complexos. No âmbito da educação, o saber ambiental questiona os paradigmas já estabelecidos e serve de fonte para a busca de novos conhecimentos: os saberes indígenas, os saberes do povo, os saberes pessoais. Tal perspectiva reflete no campo da interdisciplinaridade.

Nesta perspectiva, o projeto interdisciplinar surge no intuito de reorientar a formação ambiental e por isto, também, a formação profissional por meio de um pensamento que busca apreender a unidade da realidade para solucionar os mais diversos problemas da atual realidade. O saber ambiental busca a interdisciplinaridade, busca o convergir dos olhares dispersos dos saberes disciplinares, ao passo que, desvela a importância de uma realidade racional e funcional que elimine as divisões impostas pelo cientificismo e integre um conjunto de saberes não científicos (LEFF,2015).

Em síntese, o "saber ambiental" é um conjunto de conhecimentos e saberes que permitem ao homem se posicionar de maneira crítica em relação a racionalidade instrumental e tecnológica predominantes e, deste modo, questionar a mercantilização da 
natureza. A racionalidade ambiental é mais ampla que o saber ambiental, mas ambos estão intimamente relacionados visto que é com base no saber ambiental que se constrói a racionalidade ambiental. E como o perfil esperado de um engenheiro pode contribuir para a consolidação dessa nova racionalidade?

\section{A presença do saber ambiental nos documentos legais do curso de engenharia}

A legislação mais recente para formação do engenheiro, CNE/CES 11/2002, propõe avanços nos aspectos políticos-pedagógicos no ensino de engenharia no Brasil e mais especificamente na gestão de um perfil de engenheiro, generalista, humanista e crítico, considerando as diversas relações e a demanda social para a formação desse "novo engenheiro" (INOVA, 2006).

Esse novo perfil do engenheiro não se restringe as demandas do mercado de trabalho, e ao contrário disso, reafirma a importância de uma formação generalista, humanística e reflexiva. Para Leff (2015) o princípio que deve ser buscado pela sociedade contemporânea, e, portanto, pelos engenheiros, é baseado no pensamento complexo e crítico e não em ideais simulacros que promovem, somente, o desenvolvimento da economia capitalista em detrimento da negativação da natureza. Esse princípio é a sustentabilidade, tão importante para a consolidação da racionalidade ambiental e que integra "[...] os valores e potenciais da natureza, as externalidades sociais, os saberes subjugados e a complexidade do mundo negados pela racionalidade mecanicista, simplificadora, unidimensional e fragmentadora." (LEFF, 2015, p. 17).

Para Bazzo e Pereira (2008), o perfil do engenheiro é marcado por uma visão do todo a partir de uma análise global das partes e da interação entre elas, que lhe confere um bom domínio da realidade física e também das atividades sociais e econômicas. Sendo assim, "o engenheiro adquire durante a sua formação uma ideia integrada de seu trabalho com o ambiente que o cerca" (BAZZO; PEREIRA, 2008, p. 84). Esta visão vai ao encontro da visão de Leff (2015) que propõe um saber ambiental crítico e complexo que integra os processos de ordem natural, técnica e social, mas nunca os uniformiza. Ele valoriza a multiplicidade de experiências e práticas de cada cultura e, a partir de sua diversidade, estrutura uma nova racionalidade social (LEFF, 2015). Desta forma, o perfil esperado de um engenheiro é de um profissional que vai além do exercício de suas atividades técnicas, e que saiba o porquê e o para quê desenvolvê-las.

No interior das organizações o novo engenheiro, deve ser capaz de desempenhar a técnica aprendida no interior da escola não apenas para propor soluções que sejam tecnicamente corretas, ele deve ter a ambição de considerar os problemas em seu contexto, a partir de uma visão sistêmica, em sua inserção numa cadeia de causas e efeitos de 
múltiplas dimensões (BRASIL, 2002). E como o perfil esperado do engenheiro é apresentado nas diretrizes curriculares dos cursos que formam tal profissional?

No Brasil, a primeira escola de engenharia para civis surgiu em 1874 na cidade do Rio de Janeiro, era a chamada escola Politécnica. Já em 1876 surge a Escola de Minas, em Ouro Preto. Em 1930 o país passou por uma reforma no ensino superior que possibilitou a abertura de novos cursos de engenharia, havendo para a época um total de 27 cursos, que se encontravam distribuídos em onze instituições de ensino superior, sendo Minas Gerais o estado com o maior número, somando quatro instituições federais (TONINI, 2007).

A partir das reformas realizadas no ensino superior em 1930, iniciou-se uma luta pela regulamentação das atividades do engenheiro e somente em 1933 surge o primeiro instrumento legal especifico o Decreto no 23.569 de 11 de dezembro de 1933 (TONINI, 2007). Depois disso, houve a implementação da Lei № 5.194, de 24 de dezembro de 1966, que regulamentava o exercício das profissões de engenheiro, arquiteto e engenheiro agrônomo.

As Diretrizes Curriculares Nacionais do Curso de Graduação em Engenharia, por sua vez, são instituídas pela Resolução do Conselho Nacional de Ensino/Câmara de Educação Superior - CNE/CES no 11, de 11 de março de 2002, estabelecendo os princípios, os fundamentos, as condições e os procedimentos na formação de engenheiros. Em 2005, a Resolução no 1.010 de 22 de agosto, propõe uma revolução na concepção das atribuições profissionais do engenheiro, baseada em novos fundamentos da Lei de Diretrizes e Bases de 1996 (OLIVEIRA, 2010).

No âmbito das Diretrizes Curriculares Nacionais do Curso de Graduação em Engenharia, o artigo $3^{\circ}$ afirma que:

O Curso de Graduação em Engenharia tem como perfil do formando egresso/profissional o engenheiro, com formação generalista, humanista, crítica e reflexiva, capacitado a absorver e desenvolver novas tecnologias, estimulando a sua atuação crítica e criativa na identificação e resolução de problemas, considerando seus aspectos políticos, econômicos, sociais, ambientais e culturais, com visão ética e humanística, em atendimento às demandas da sociedade. (BRASIL, 2002).

Assim, a partir dessa premissa percebe-se que o perfil esperado de um engenheiro é de um profissional que seja comprometido com o saber ambiental. Já que o mesmo deve perceber o ambiente de um modo mais complexo que a análise naturalista permite interpretá-lo. Tal premissa permite, também perceber que o saber esperado dos engenheiros é um saber complexo do mundo, um saber que requer a reconsideração dos demais seres vivos, e o fim da desigualdade social. Para Leff (2015) esse saber envolve os processos naturais e, principalmente, os processos sociais. É uma categoria sociológica, relativa a uma racionalidade social com seus costumes, valores e saberes. 
Contudo, quando analisado os demais artigos das diretrizes percebe-se que, embora, o perfil esperado do engenheiro seja de um profissional generalista, o que se percebe, na verdade, é um profissional especializado. Em seu Artigo $4^{\circ}$ as diretrizes destaca dentre as competências e habilidades esperados de um engenheiro: aplicar conhecimentos matemáticos, científicos, tecnológicos e instrumentais à engenharia; projetar e conduzir experimentos e interpretar resultados; conceber, projetar e analisar sistemas, produtos e processos; planejar, supervisionar, elaborar e coordenar projetos e serviços de engenharia; identificar, formular e resolver problemas de engenharia; desenvolver e/ou utilizar novas ferramentas e técnicas; supervisionar a operação e a manutenção de sistemas; avaliar criticamente a operação e a manutenção de sistemas; comunicar-se eficientemente nas formas escrita, oral e gráfica; atuar em equipes multidisciplinares; compreender e aplicar a ética e responsabilidade profissionais; avaliar o impacto das atividades da engenharia no contexto social e ambiental; avaliar a viabilidade econômica de projetos de engenharia; assumir a postura de permanente busca de atualização profissional.

Isto evidencia o que Leff (2015) chama de tecnologização da vida e a economização da natureza. Além disso, em nenhum momento se prioriza um saber questionador, transformador e recreativo, que desvele a enganosa transparência dos sinais do mercado globalizado e do iluminismo do conhecimento científico e moderno. Ao que tudo indica o perfil esperado é de um engenheiro que saiba pensar e executar a sua profissão, mas, ainda pouco conscientizado sobre a importância de sua atuação na busca por uma melhor qualidade de vida.

Leff (2015) ainda afirma que o saber ambiental não é exclusivo das disciplinas ambientais, já que sua abrangência vai além das causas estritamente ecológicas. $O$ conceito de saber ambiental abrange ética, conhecimentos práticos e até mesmo saberes tradicionais. Segundo o autor, o saber ambiental vai em oposição ao método científico moderno centrado em seus micro objetos de pesquisa que, por diversas vezes, desconhecem processos complexos. É por isto que o saber ambiental enfatiza a unidade do conhecimento a partir da valorização da diversidade e da diferença. Tal perspectiva reflete no campo da interdisciplinaridade. Mas o que se percebe nas diretrizes de engenharia é que todo o curso de Engenharia, "deve possuir em seu currículo um núcleo de conteúdos básicos, um núcleo de conteúdos profissionalizantes e um núcleo de conteúdos específicos que caracterizem a modalidade." (BRASIL, 2002).

Ainda neste contexto de fragmentação do conteúdo, um outro problema é evidenciado: a criação do conteúdo "ciências do ambiente". Conforme Leff (2015) é preciso muito mais que a criação das "ciências ambientais". Na verdade, é esta interpretação ingênua que levou a criação de um conjunto de ciências que se satisfaz apenas em internalizar em seus conceitos e análises, os efeitos socioambientais negativos que a 
racionalidade instrumental gera. É por isto que a complexidade ambiental exige uma análise sociológica de desenvolvimento do conhecimento, como uma problematização dos paradigmas teóricos e metodológicos a partir de um processo transdisciplinar que visa a construção de uma nova racionalidade social (LEFF, 2002).

No artigo $5^{\circ}$ das diretrizes, os dois parágrafos procedentes destacam atividades previstas para garantir o perfil esperado do engenheiro,

$\S 1^{0}$ Deverão existir os trabalhos de síntese e integração dos conhecimentos adquiridos ao longo do curso, sendo que, pelo menos, um deles deverá se constituir em atividade obrigatória como requisito para a graduação.

$\S 2^{\circ}$ Deverão também ser estimuladas atividades complementares, tais como trabalhos de iniciação científica, projetos multidisciplinares, visitas teóricas, trabalhos em equipe, desenvolvimento de protótipos, monitorias, participação em empresas juniores e outras atividades empreendedoras. (BRASIL, 2002).

Em nenhum momento do documento são citadas atividades do projeto didáticopedagógico envolvendo a participação da sociedade, ou, simplesmente, a comunidade local. Para Leff (2015), é preciso investir em formação sem desmerecer a complexidade e as particularidades regionais. Em outras palavras, é preciso analisar o mundo como um todo e ver toda a sua complexidade a partir de uma análise holística e sistêmica que valorize todas as identidades culturais. $O$ ensino tradicional falha é exatamente nessa falta de impulsionar e orientar as capacidades cognitivas do aluno e por não estar vinculado aos problemas de seu contexto sociocultural.

Por fim, em nenhum momento das diretrizes percebe-se a preocupação na promoção da sustentabilidade. Além disso, disciplinas como sociologia ou filosofia, sequer são mencionadas. Como pensar em um profissional generalista, humanista e crítico, sendo que na verdade, sua formação está toda voltada para a formação de habilidades e competências técnicas?

\section{Considerações Finais}

A crise ambiental é apenas um sintoma de uma crise maior e mais radical, caracterizada aqui como crise da democracia. Essa crise atinge os âmbitos social, político e econômico e nos mostra que os pilares dos quais os argumentos universais parecem validos, ciência - razão - progresso - desenvolvimento, já não causam apenas o bem-estar que precisamos, mas também a aflição, a escravidão e a destruição (MORIN,1998, apud, GUIMARAES, 2010). 
No âmbito da educação superior em Engenharia, é importante entender as limitações presentes nas diretrizes que traçam o perfil do profissional engenheiro. As diretrizes propõem uma formação "humana, critica e reflexiva [...]", porém em seu currículo básico as disciplinas com conteúdos não técnicos apenas tangenciam o currículo. Ao propor avaliar os impactos das atividades da engenharia no contexto social e ambiental, a diretriz não leva em consideração a promoção da sustentabilidade de forma transdisciplinar, ocasionando a fragmentação dos conteúdos e da realidade. Considerando que em boa medida as mudanças realizadas nas diretrizes de 2002 se encerram em atualizações que moldam o currículo como requer a legislação.

E evidente a ausência de discussões de maior peso sobre as responsabilidades sociais e ambientais da profissão, desta forma para se formar profissionais da engenharia que sejam capazes de formular sínteses socioambientais, exige um esforço criativo que significa reformular os currículos desses cursos (TOZZONI-REIS, 2004).

Propor a estruturação de novos currículos que auxiliem na construção de um saber ambiental, de forma transdisciplinar, incorporando diversos saberes das diversas áreas nessa formação é essencial para que o perfil do novo engenheiro seja menos tecnicista e que atinja a finalidade de formar um profissional generalista, humanista e crítico, como descrito nos documentos legais. Por fim, outro grande desafio reside no fato de que "não se pode reformar a instituição sem uma prévia reforma das mentes, mas não se podem reformar as mentes sem uma prévia reforma das instituições" (MORIN, 2004, p.99).

\section{Referências}

BIHR, Alain. A crise ecológica. In: BIHR, Alain. Da grande noite à alternativa: o movimento operário europeu em crise. Tradução de Wanda Nogueira Caldeira Brant. São Paulo, Boimtempo, p.123 - 141. 1998.

BRASIL. Ministério da Educação e do Desporto. Diretrizes Curriculares Nacionais do Curso de Graduação em Engenharia. Resolução CNE/CES 11/2002. Diário Oficial da União, Brasília, 9 abr. 2002.

HORKHEIMER, Max. Meios e fins. In: HORKHEIMER, Max. Eclipse da razão. São Paulo: Centauro, 2010. 192p. Disponível em: <https://sociologianomedio. files.wordpress.com/2014/04/eclipse-da-razc3a3o.pdf> Acesso em: 10 Jun. 2016.

INOVA: IEL.NC,SENAI.DN. Inova engenharia. Propostas para a modernização da educação em engenharia no Brasil. Brasília: IEL.NC, SENAI.DN, 2006.

LAUDARES, J. B. A formação do engenheiro em duas instituições mineiras: o CEFETMG e o IPUC-MG. 1992. Dissertação (Mestrado em Tecnologia - Área de concentração em 
Educação Tecnológica) - Centro Federal de Educação Tecnológica de Minas Gerais, Belo Horizonte.

LEFF, Enrique. Saber ambiental: sustentabilidade, racionalidade, complexidade, poder. $11^{\text {a }}$ Edição. Petrópolis, RJ. Editora Vozes, 2015.

LOPES, Ana Claudia Cardoso. O Lugar da sustentabilidade nos currículos de cursos de engenharia civil em duas Instituições Federais Mineiras. 2014. 181f. Dissertação apresentada ao Curso de Mestrado em Educação Tecnológica do Centro Federal de Educação Tecnológica de Minas Gerais - CEFET-MG. Belo Horizonte, 2014.

MARCUSE, Herbert. Algumas implicações sociais da tecnologia moderna. In: KELLNER, Douglas (ed); MARCUSE, Herbert. Tecnologia, guerra e fascismo. São Paulo: UNESP, 1999, p. 71-104. Disponível em: <http://docslide.com.br/documents/algumasimplicacoes-sociais-da-tecnologiamoderna-herbert-marcuse.html> Acesso em: 10 Jun. 2016. MORAES, M.C. O paradigma educacional emergente. Campinas: Papirus Editora, 1997. MORIN, Edgar. A cabeça bem-feita: repensar a reforma, reformar o pensamento. Tradução de Eloá Jacobina. 9. ed. Rio de Janeiro: Bertrand Brasil, 2004.

MORIN, Edgar. Sociologia: a sociologia do microssosial ao macroplanetário.

GUIMARÃES, S.S.M. O Saber Ambiental na Formação dos Professores de Biologia. São Paulo: UNESP, 2010. Tese de Doutorado.

RABELO, Andréia Maria Pinto. Aporias da Sustentabilidade: Análise da Agenda 21 Brasileira a partir da Teoria Crítica. 2007. 143 f. Dissertação (Mestrado em Educação, Cultura e Organizações Sociais) - Fundação Educacional de Divinópolis, Universidade do Estado de Minas Gerais, Divinópolis, 2007.

TONINI, A. M. Ensino de engenharia: as atividades acadêmicas complementares na formação do engenheiro. Tese (Doutorado em Educação) Universidade Federal de Minas Gerais. Faculdade de Educação. Belo Horizonte - MG, 2007.

TOZONI-REIS, M. F. C. Educação ambiental: natureza, razão e história. Campinas: Autores Associados, 2004. 